\title{
THE INTELLIGENT SYSTEM FOR AUTOMOTIVE FUELS QUALITY DEFINITION
}

\author{
Volodymyr Drevetskiy, Marko Klepach \\ National University of Water Management and Natural Resources Use, Rivne, Ukraine
}

Abstract. An intelligent system, based on hydrodynamic method and artificial neural networks usage for automotive fuels quality definition have been developed. Artificial neural networks optimal structures for the octane number of gasoline, cetane number, cetane index of diesel fuel definition have been substantiated and their accuracy has been analyzed. The implementation of artificial neural networks by means of microcontroller-based systems has been considered.

Keywords: Hydrodynamics, Artificial neural network, Fuels, Real-time systems

\section{INTELIGENTNY SYSTEM DO OCENY JAKOŚCI PALIW SAMOCHODOWYCH}

Streszczenie. Opracowano inteligentny system bazujacy na metodach hydrodynamicznych i sieci neuronowej wykorzystywany do oceny jakości paliwa samochodowego. Przedstawiono optymalne struktury sieci neuronowych do oceny liczby oktanowej benzyny, liczby cetanowej i indeksu cetanowego dla oleju napędowego oraz przeanalizowano ich dokładności. Rozważono możliwość implementacji sieci neuronowych z wykorzystaniem mikrokontrolera.

Słowa kluczowe: hydrodynamika, sztuczna sieć neuronowa, paliwa, system czasu rzeczywistego

\section{Introduction}

Efficiency of automotive fuels usage requires continuous operative quality control. Modern devices and methods do not provide a comprehensive operational quality control, adapted only to a certain type of petroleum product, are unable to be integrated into industrial automation and ERP- class systems. Consequently there is a necessity of building intelligent informationmeasurement systems (IMS), which combines the techniques of classical hydrodynamics and modern intelligent components based on programmable logic controllers.

\section{The basis for the system design}

We developed methods [1] and synthesized based on them an intelligent information-measuring system [2] that provide hydrodynamic method of determining in real time mode the physical and mechanical properties of petroleum products such as gasoline (density), diesel fuel (density, viscosity), oil and fuel oil (density, viscosity, viscosity-temperature characteristics).

The aim of the research is to determine on the basis of known values of density and viscosity such parameters as octane number, cetane number and index using artificial neural networks (ANN). To provide the measurement process control, implementation of ANN, flexibility and compatibility with modern systems of industrial automation we have to use the programmable logic controllers.

Information-measuring system shall have a modular structure to facilitate its construction, maintenance and integration capabilities. So for the collection of primary data and the implementation of control actions should be used only standard industrial sensors and executive mechanism with unified input and output signals.

Human-machine interface of measurement system has to be realized by means of operator graphic touch panel or computer.

\subsection{Hydrodynamic method}

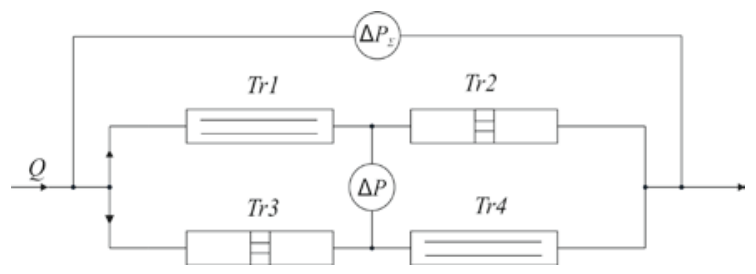

Fig. 1. Structure of throttle bridge converter

The measurement process is based on hydrodynamic methods of kinematic viscosity and density definition. Sensing element is a throttle bridge converter (TBC) [3]. Hydraulic bridge (Fig. 1) formed by two laminar Tr1, Tr3 and two turbulent Tr2, Tr4 throttle elements. The principle of measurement is in continuous pumping of the exploring oil products through the TBC and automatic astatic balancing of the bridge by changing the volumetric flow rate $\mathrm{Q}$ of the product.

By value of volumetric flow and total pressure drop $\Delta P_{\Sigma}$ on TBC determined at the time of balance (when $\triangle P$ - pressure drops in the indicator diagonal equal to zero) the next parameters are calculated:

Kinematic viscosity:

$$
v=k Q
$$

where: $k$ - coefficient that depends on the geometrical dimensions of the measuring bridge throttles.

Density of oil products:

$$
\rho=k_{\rho} \frac{\Delta P_{\Sigma}}{Q^{2}}
$$

where: $k_{\rho}$ - constant of proportionality, determined on construction and geometric dimensions of throttles.

Dynamic viscosity:

$$
\mu=v \rho
$$

To improve the measurement accuracy TBC must be equipped with a thermostat, because the density and viscosity dependent on temperature.

\subsection{Determination of oil products viscosity- temperature characteristics}

Presence of thermostat in IMS allows us to determine viscosity-temperature characteristic by fixing the appropriate values of temperature and viscosity during heating. At some moment of time after the change in temperature by $0.5^{\circ} \mathrm{C}$, measured temperature and kinematic viscosity values are recorded in the intermediate base. After filling the intermediate database by least squares method, the approximating polynomial coefficients are calculated that mathematically describes the curve of viscosity on temperature. The real values of temperature and viscosity are plotted at the schedule as points with interval changes in temperature by $5^{\circ} \mathrm{C}$ and a mathematical relationship depicted as a continuous curve in a given range of temperature change. Thus there is a possibility of visual comparison of obtained and calculated data.

To assess the accuracy of the device as the test environment was taken jet fuel type $\mathrm{T}-1 \mathrm{C}$ and received its viscositytemperature characteristic (Fig. 2)

Viscosity-temperature characteristic of studied sample of jet fuel is described by a third degree polynomial:

$$
v=-0.000007 \mathrm{t}^{3}+0.0013 \mathrm{t}^{2}-0.0931 \mathrm{t}+3.3557
$$




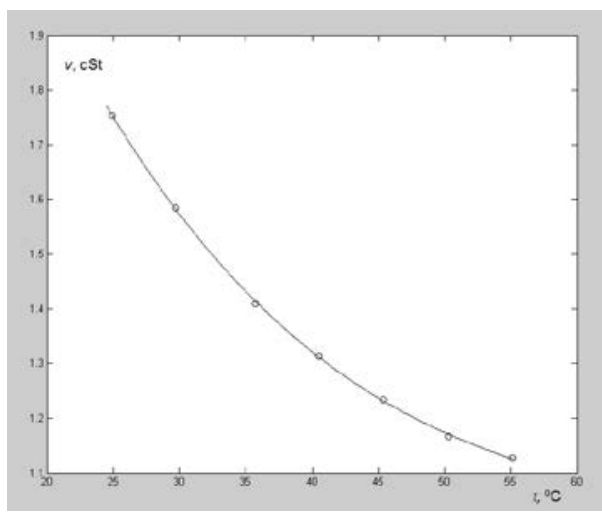

Fig. 2. Viscosity-temperature characteristic of jet fuel T-1C

Comparative analysis of the calculated values with the actual values of the kinematic viscosity showed that the absolute error is less than $0.04 \mathrm{cSt}$, and the relative error is under $3 \%$.

\subsection{Design of artificial neural networks}

Training and testing ANN for determining octane number based on premeasured density, cetane number and index by density and viscosity performed according to the data from the certificates of laboratory tests. Characteristics of datasets are given in Table 1.

Table 1. The training and testing data sets characteristics

\begin{tabular}{|c|c|c|c|c|c|}
\hline \multirow{2}{*}{ № } & \multicolumn{2}{|c|}{ Artificial neural network } & \multicolumn{2}{|c|}{ Dataset, points } & \multirow{2}{*}{ Fuel } \\
\cline { 2 - 5 } & Input & Output & Train & Test & Octane \\
1 & Density & 150 & 84 & $\begin{array}{c}\text { Gasoline A80, A92, } \\
\text { A95, Premium A95 }\end{array}$ \\
\hline 2 & $\begin{array}{c}\text { Density, kinematic } \\
\text { viscosity }\end{array}$ & $\begin{array}{c}\text { Cetane } \\
\text { number }\end{array}$ & 29 & 16 & $\begin{array}{c}\text { Premium summer } \\
\text { diesel }\end{array}$ \\
\hline 3 & $\begin{array}{c}\text { Density, kinematic } \\
\text { viscosity }\end{array}$ & $\begin{array}{c}\text { Cetane } \\
\text { index }\end{array}$ & 29 & 16 & $\begin{array}{c}\text { Premium summer } \\
\text { diesel }\end{array}$ \\
\hline
\end{tabular}

Training and testing of networks was carried out by means of application Neural Network Toolbox from Matlab software package. For best results of the fuel quality parameters definition accuracy we used the network models such as Feed-forward (FF) and Cascade-forward (CF) without delays, because previous research should not affect the next results. Given that the nature of the relationship between the parameters are not defined beforehand, using different activation functions of neurons (tansig, purelin, logsig) with different number of layers and neurons in layers. Considering that nature of the relationship between the parameters are not defined beforehand, we used different activation functions of neurons (tansig, purelin, logsig) with different number of layers and neurons in layers. The number of neurons in the layers of neural network depends on the complexity of the relationship between input and output parameters. However, too large number of them increases the difficulty and thus calculation and learning time. In addition, it can lead to over training of ANN, that means excessive adaptation to training set that negatively affects the accuracy of the output value. Therefore, the number of neurons in the layers of the models was different and was set in the range from 4 to 20 .

Verification of models performance was carried out using additional data sets that were not used during training. The main criteria for choosing the optimal structure and parameters of the neural networks were the mean square and mean absolute errors.

As a result of comparison the octane number values determined using ANN with real the most effective was threelayered Cascade-Forward neural network (Fig. 3), with 10 and 6 neurons in the hidden layers and the transfer functions tansigpureline-pureline.

Mean square error of octane number definition is 0.063 , mean absolute error (MAE) 0.193 octane number units.

After analyzing the accuracy of models for cetane number definition the best performance had the ANN with mean square error of 0.2 and mean absolute error of 0.38 units. The structure of this neural network is shown on Fig. 4.

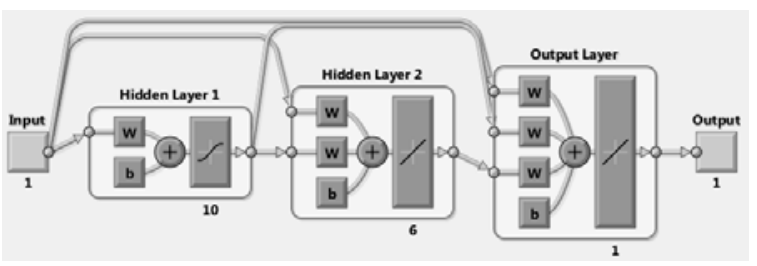

Fig. 3. Structure of ANN for the gasoline octane number definition

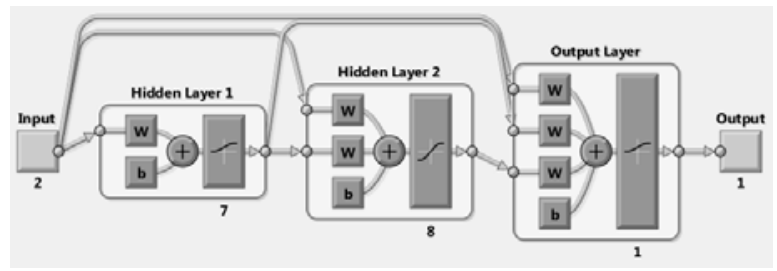

Fig. 4. Structure of ANN for the diesel fuel cetane number definition

This is CF-class, three-layered network with transfer functions logsig tansig-logsig which has 7 and 8 neurons in the hidden layers.

By analysis results of neural network models for the cetane index definition most effective appeared the CF-class, two-layer artificial neural network with linear transfer functions and 11 neurons in the hidden layer (Fig. 5).

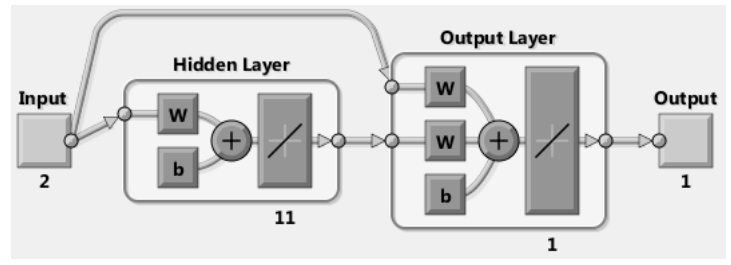

Fig. 5. Structure of ANN for the diesel fuel cetane index definition

The performance of this artificial neural network was mean square error -0.11 and the average absolute error of 0.27 units of cetane index.

In all 3 cases, neural networks of Feed-Forward class although showed similar in accuracy results but were less effective. In general, as the analysis revealed, the accuracy is high enough to use the ANN in express analysis of fuels quality. Also, the adaptation of networks to large data set can significantly improve their performance.

\section{The IMS structure}

The main requirements for the structure of IMS is the control of process primary information parameters measuring using hard real-time, possibility of neural networks implementation, temperature stabilization, flexibility in exploitation by using modular structure and standard industrial equipment. Block diagram of the system we have designed is shown in Fig. 6.

In this case, the optimal choice is the use of industrial programmable logic controllers, as the basic unit for operating, processing and transmitting information. To provide humanmachine interface we can use operator graphic touch panel or PC in case of integration into a higher automation systems.

The VIPA PLC software designed so, that through analog and discrete inputs/outputs to provide collection of information from sensors, that are installed to the throttle bridge converter (Automatic TBC control), to process information signals from sensors and to transmit them to the upper levels and to give control influences to the executive mechanisms of measuring process (Measurement process control).

Accoding to the hydrodynamic method for viscosity and density measurement using the TBC our system equipped with two manometers made by ABB, one to measure the total pressure drops across the bridge scheme and second for Automatic TBC control sustem balanciation, thermoreresistor by OWEN, volumetric flow sensor by Kobold. 


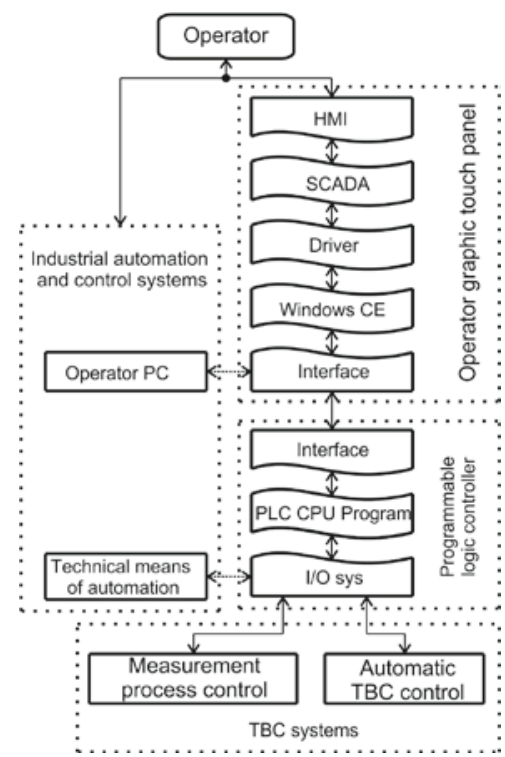

Fig. 6. Block diagram of the intelligent system

To provide the measurement process it is required the throttle bridge converter to be equipt with the balanciation and temperature stabilization subsystems. Changes in viscosity leads to the TBS to unbalanced unbalanced state. Speed of the bridge scheme balancing by influencing on the volumetric flow is very important to ensure the system performance, because the measurements could be made only in the balance state so we applied PID-controller.

For parametric optimization of the automatic balancing subsystem we built its Simulink-model [4]. Using the Simulink library Design Optimization we received optimal PID-controller parameters. Using the Real Time Windows Target together with PCI-card Advantech for PC [5] allow us to simulate subsystems in real-time mode. The results of automatic balancing subsystem modeling with step changes of kinematic viscosity are shown in Fig. 7.

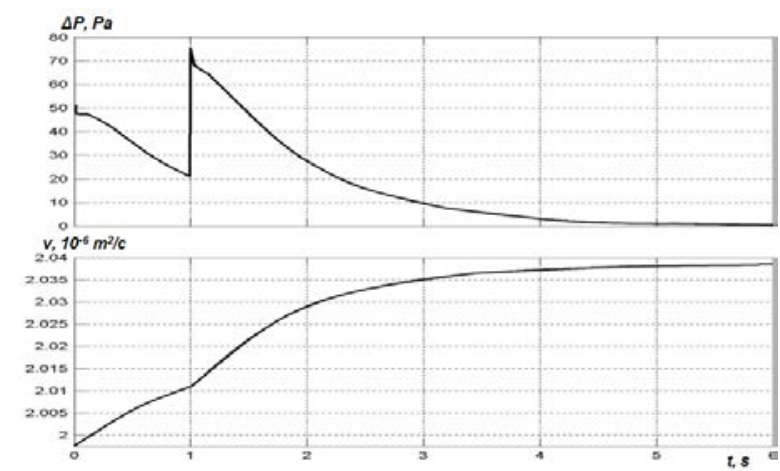

Fig. 7. The simulation of automatic balancing subsystem results

One can see that the reaction of DMP to viscosity changes is accompanied by two jumps, due to its design and hydraulic transients. Immediately after the pressure jump system produces control influences to change the volumetric flow and balaces the throttle bridge converter for time less than $5 \mathrm{~s}$, indicating its high efficiency.

System of the product temperature stabilization works on PIDPWM control law that eliminates pre-defined error which appears when using the classical two-position controllers with the dead zone.

\section{Results}

Database of artificial neural networks can be realized by meams either PLC through code generation from Simulink-model using PLC Coder, or operator garaphic touch panel with SCADAsystem preinstalled.
To implement the human-machine interface we used VIPA Touch Panel with Movicon SCADA-system. The touch panel graphic user interface of measurement process is shown on Fig. 8.

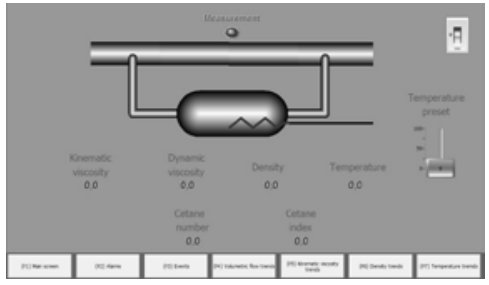

Fig. 8. Operator graphic user interface

Given previous research, we have developed a laboritary prototype of an intelligent system for oil products quality characteristics definition (Fig. 9).
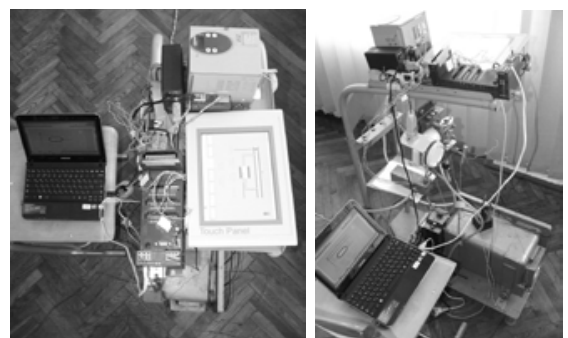

Fig. 9. A prototype of intelligent system

\section{Conclusions}

A prototype of intelligent information-measuring system for the oil products kinematic and dynamic viscosity, viscositytemperature characteristic, density, octane number, cetane number and index definition with high accuracy has been developed.

\section{Bibliography}

[1] Drevetskiy V., Kvasnikov V.: Oil products quality control by the hydrodynamic method. Bulleting of Engineering Academy of Ukraine 3,4/2008, p. 87-89.

[2] Drevetskiy V., Klepach M.: The information-measurement system of oil products quality. MDMTNDTTDE, Ivano-Frankivsk 2011.

[3] Drevetskiy V.: Measurements of physical and mechanical properties of liquids with the throttle converter. MSR, Dnipropetrovsk 2003.

[4] Drevetskiy V., Klepach M.: Dynamic properties of the viscosity and density automatic analyzer for oil products. Bulleting of Engineering Academy of Ukraine 1/2009, p. 128-131.

[5] Drevetsky V., Klepach M. Real time modeling of the information-measurement system for physical-chemical parameters of oil products. Mathematical Machines and Systems. 2/2011, p. 81-84.

D.Sc.(Technical), prof. Volodymyr Drevetskiy e-mail: Westra@rv.uar.net

Vice President of Engineering Academy of Ukraine, Head of Automation, electrical engineering and computer integrated technologies Department (NUWMNRS)

The main scientific direction - development of methods and devices for continuous automatic monitoring of the physical and mechanical parameters of Newtonian and non-Newtonian fluids, as well as the quality of oil products. Author of over 200 scientific papers, including 51 patents, most of which are implemented in production.

\section{M.Sc. Marko Klepach}

e-mail: KlepachMM@ukr.net

Research engineer of computer systems and automation, postgraduate student, assistant of the Department of Automation, electrical engineering and computer integrated technologies.

The main scientific direction - automation of oil refining technological processes, construction of data collection, information-processing and industrial automation systems; research and design of artificial neural networks models for industrial automation and measurement systems; mathematical modeling of physical and chemical processes.

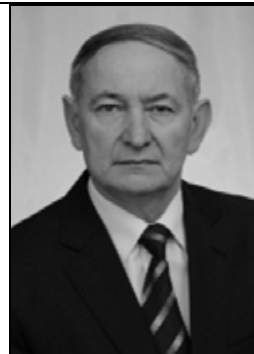

otrzymano/received: 01.06.2013

przyjęto do druku/accepted: 03.06 .2013 